\title{
BUENOS AIRES METROPOLITANA. POLITICA Y GESTIÓN DE LA CIUDAD
}

Pedro Pirez (1994)

Centro Editor de América Latina/Centro, Estudios

Sociales y Ambientales

(Bibliotecas Universitarias)

\section{Arteaga, Renato}

Arquitecto por la Universidad de Ingeniería, exbecario del Estado Peruano. Magíster en Planificación Urbana Regional por la Universidad de Buenos Aires. Doctorando en Estudios Urbanos por la Universidad Nacional de General Sarmiento. Docente de la Universidad Nacional de Ica. Integrante de la comisión de urbanismo del Colegio de Arquitectos del Perú, provincia de Ica. arqteaga_uni@hotmail.com

\section{Resumen}

La propuesta central del autor radica en identificar como problemática la gestión metropolitana bonaerense. Comprueba que las entidades individuales (municipales) tienen inconvenientes en gestionar eficientemente los servicios urbanos, que en la mayoría de casos tienen alcances multi-jurisdicionales. Al final de su estudio propone la creación de una entidad política metropolitana capaz de superar estas deficiencias al tener una visión global de ciudad. En esta breve reseña seguiremos las pautas argumentativas del autor en cinco puntos: empieza con una descripción sobre la dualidad de la ciudad; en segundo momento, pasa a estudiar cómo se administran la ciudad central y la periférica; en un tercer momento describe las condiciones en que encuentra la gestión de ambas realidades; posteriormente estudia las razones de los intentos fallidos y finalmente propone, groso modo, la necesidad de la creación de una autoridad metropolitana. 


\section{Buenos Aires: ciudad central y periférica}

La metrópoli bonaerense está conformada por dos unidades territoriales marcadamente diferentes, la ciudad histórica de Buenos Aires (ciudad central) y el área conurbana llamada también ciudad periférica. Para inicios de los 90, la primera concentraba tres millones de habitantes y ocupaba $200 \mathrm{~km}^{2}$ de superficie, mientras la segunda sobrepasaba los siete millones y se asentaba sobre un área de $4000 \mathrm{~km}^{2}$. Esta última está conformada por diecinueve partidos distribuidos en dos coronas alrededor de la ciudad central. Para entonces esta gran metrópoli cobijaba a la tercera parte de la población argentina. Al pasar los años, durante la primera década el siglo XX se consolida la formación de esta urbe gracias a su imponente base económica de la industrialización sustitutiva de importaciones, que apuntaló su posicionamiento sobre las demás urbes argentinas (la consolidación de la industria significó una fuerte atracción para la población del interior y provocó fuertes corrientes migratorias a la naciente metrópoli). El progresivo crecimiento económico se expresó en la modernización de la ciudad central, sobre todo en el mejoramiento del equipamiento y servicios urbanos ${ }^{1}$. La ciudad periférica se consolidó gracias al sistema de trenes. La ciudad se expandió hacia el norte, el cual fue ocupado por sectores medianos y altos, mientras los sectores oeste y sur fueron ocupados por clases de menores recursos. La población migrante se localizó sobre suelo más accesible a su bolsillo, pero a su vez más alejados del núcleo central; así se crearon las primeras villas, que datan de los años 30. En este contexto de expansión de la metrópoli, empezaron a observarse notables diferenciaciones entre las ocupaciones de la ciudad central y la periférica. Citando a RoMERo (1984) menciona:

La ciudad metropolitana se convirtió en esos años en una heterogénea y diversificada sociedad. La población de los suburbios, que alimentaban con su trabajo a las actividades económicas irrumpió social y políticamente en el centro. Las manifestaciones del 17 de octubre de 1945 son un claro ejemplo. Los “descamisados” refrescándose en las fuentes de la plaza de mayo, frente a la casa de gobierno con su símbolo. Para la ciudad central eso fue un descubrimiento. De allí los calificativos de cabecitas negras, o de "aluvión zoológico” con las clases altas mencionaba a esos habitantes metropolitanos (Romero, 1984, p. 23).

Este escenario dicotómico mostró a mediados del siglo XX la creciente periferización de la ciudad, y volvió a hacer más visibles posteriormente las políticas urbanas implementadas durante la dictadura de los 70. Los efectos de tales decisiones mostraron mayor intensidad en el contraste entre la ciudad central y la periférica.

Cuaderno Urbano. Espacio, Cultura, Sociedad - Vol. 31 - N. ${ }^{\circ} 31$ (Diciembre de 2021) - Pp. 228-233 - ISNN1666-6186
1. Para inicios del siglo $X X$ esta ciudad se distinguía del resto de capitales latinoamericanas por contar con un óptimo sistema de redes de gas domiciliario (1856), de dotación de agua y desagüe (1905), de distribución de energía eléctrica (1887), de subte (1910), de redes de telefonía (1905) y aeropuerto (1940). 
2. Durante la década de los 70, el gobierno dictatorial mostró una clara intención política de atender las necesidades e intereses de los estratos sociales más conservadores y mejorar las condiciones urbanas de sus lugares de residencia concentrados en CABA, $y$ sacar de allí a quienes no merecían permanecer (en alusión a la tesis de Ozlack, merecer la ciudad). Aquí muestra el autor que la política de este gobierno en la ciudad se concentró en practicar una acción urbana de acupuntura, en la intervención de proyectos específicos destinados a mejorar la ciudad central.

\section{Administración dicotómica de la metrópoli}

El tipo de gobierno en la administración de una ciudad contribuye a que esta resulte inclusiva o exclusiva. Los efectos de las políticas urbanas implementadas por el gobierno dictatorial ${ }^{2}$ se caracterizaron por fortalecer la primacía de la ciudad central en detrimento de la periférica. Durante ese período se aplicó un sistema de intervención urbana tipo "acupuntura”, consistente en las siguientes acciones: se emplearon políticas de desindustrialización, así como la redistribución regresiva del ingreso, lo cual contribuyó a la concentración de la riqueza; se consolidaron las transnacionales; se eliminó la ley de inquilinato (lo que ocasionó el desplazamiento de la clase media baja a la ciudad periférica); se propuso un plan de erradicación de villas (que expulsó a la población de escasos recursos a los confines de la ciudad). Los resultados de este tipo de políticas tuvieron diferentes efectos sociales en posteriores décadas. Para la década de los 90 llegaron a medio millón los inquilinos desalojados de la ciudad central, reaparecieron aproximadamente 5000 villeros en distintas ubicaciones de la metrópoli, se incrementó la toma de casas antiguas abandonadas y finalmente creció la pobreza en paralelo con el incremento de los índices de hacinamiento, déficit habitacional y precarización laboral.

Tres décadas después de la implementación de este tipo de políticas, la transformación de la ciudad Metropolitana de Buenos Aires se dio en términos de incremento de la desigualdad social. Desde el ámbito territorial, se encuentran dos tipos de ciudades marcadamente diferentes. La primera es la ciudad central, de mayor antigüedad y de ocupación por un estrato social alto-mediano, con un sistema de servicios relativamente antiguo, pero en funcionamiento, cuya actividad predominante es el sector terciario.

\section{La problemática de la gestión de servicios}

Posteriormente a la descripción de las políticas urbanas aplicadas en Buenos Aires, el autor aborda la problemática de su gestión. Aquí argumenta que, a pesar de las diferentes agencias gubernamentales promotoras de la planificación en servicios, estas se dieron en un nivel elemental y en un contexto de limitada capacidad técnico-jurídica. La fragmentación y heterogeneidad de su gestión es expresada en las dimensiones normativa, territorial y técnica. La existencia de una base legal conformada por una multiplicidad de leyes provenientes de los cuatro niveles de gobierno para intervenir en temas de servicios urbanos ha generado dificultades en las mesas de negociaciones, en donde se traslucen las oposiciones, intereses 
y diferencias políticas entre distintos partidos y niveles de poder que conllevan a la discrepancia entre el otorgamiento de recursos para lograr el avance de diferentes proyectos. La fragmentación territorial se debe a que muchas veces la ejecución de proyectos implica el uso de suelo de distintas jurisdicciones, y muchos municipios no consideran tales delimitaciones jurisdiccionales. La fragmentación técnica se expresa en los bajos niveles de coordinación entre diferentes áreas técnicas de los gobiernos locales. Este apartado concluye en la naturaleza heterogénea y diferenciada de gestión del área metropolitana, ejemplificada en el caso del CEAMSE ${ }^{3}$.

\section{Recursos y financiamiento de la gestión metropolitana}

Parte de los inconvenientes mostrados se debe a que el sistema de financiamiento de las unidades políticas encuentra dos mecanismos diferenciados en términos de autonomía e inversión. La ciudad central goza de cierta autonomía financiera, debido a que el 89 \% de sus recursos proviene de ingresos propios correspondientes a tasas, impuestos, licencias, etc. Además de ello, tiene la capacidad de conseguir empréstitos internacionales. Esta administración para fines del siglo XX invertía en promedio 900 pesos por habitante en materia de gastos por administración de servicios públicos. Del otro lado, se encuentra la ciudad periférica, cuya independencia financiera es débil, ya que sus ingresos propios representan el $60 \%$, y lo restante proviene de transferencias por parte del Gobierno provincial. Son municipios que no pueden tener capacidad de endeudarse en la banca internacional y, sobre todo, efectúan una inversión de 300 pesos por habitante. Aquí nuevamente el autor argumenta las diferencias no solamente en la conformación física de los sistemas, sino también en sus mecanismos de financiamiento de la metrópolis bonaerense.

\section{Intento de institucionalizar la autoridad metropolitana}

El trabajo concluye haciendo un breve recorrido por los intentos de institucionalizar una autoridad autónoma de la ciudad, el cual se remonta a antiguas experiencias desde la década de los 50, cuando se trató de crear esta institución. Desde aquella fecha hasta la actualidad han existido varios intentos entre algunas instituciones de rango metropolitano; algunas de ellas fueron SIMEB $^{4}$, CONHABITAT $^{5}$, CONADE $^{6}$ y CONAMBA $^{7}$. Sin embargo, estos agentes gubernamentales tuvieron inconvenientes en cumplir sus objetivos. Entre algunas razones que menciona el autor, es la primacía de un modelo centralizador y poco democrático lo que limita la
3. Entidad encargada de la gestión y administración de residuos sólidos.

\section{Sistema Metropolitano} Bonaerense.

\section{Consejo Nacional del} Hábitat.

6. Consejo Nacional para el Desarrollo.

7. Comisión Nacional para el Área Metropolitana de Buenos Aires. 
participación de municipios pequeños. Se caracterizaron por ser procesos netamente tecnocráticos, alejados de capacidades sociales e institucionales. La discontinuidad de esfuerzos fue otra dificultad, ya que los gobiernos que sucedieron anularon la posibilidad de continuar con tales iniciativas.

\section{Anotaciones sobre la obra}

El tema que aborda Pirez es central y vigente. El problema entre la esfera técnica y política es cotidiano. La gestión del sistema metropolitano bonaerense y las complejidades de su administración que se dan desde diferentes jurisdicciones y superposición de niveles de gobierno son una muestra. La estrategia de ubicar el problema desde la intersección entre el ámbito político y el técnico permite ver las dificultades de la gestión y la consolidación política en un conglomerado de fragmentos gubernamentales.

El autor aboga por la creación de una autoridad metropolitana que supere la dificultad de tener dos administraciones parciales correspondientes a la ciudad central y la periférica. Sin embargo, esta propuesta implicaría tres consecuencias: una sería la pérdida de poder del conjunto de unidades políticas que conforman el AMBA, con el propósito de cederla a una instancia superior en el ámbito de planeamiento. En tal caso la resolución se encontraría en la arena política y no en la técnica. Una segunda consecuencia, aún más delicada, es la siguiente cuestión: ¿cómo lograr una autoridad metropolitana si no existe una representación social que así lo exija? La empresa de auspiciar una demanda a la sociedad de exigir la promoción de una entidad supramunicipal en la metrópoli es un arduo esfuerzo. Primero porque la población no está preparada para exigir este tipo de propuestas; sus requerimientos son más concretos y comunes; segundo, por el inconveniente de la existencia de dos identidades históricamente creadas, entre el porteño y el bonaerense (cuyas diferencias se basan en connotaciones sociales, económicas) que dificultan tener una identificación con el AMBA. En consecuencia, sostener que por el simple hecho de crear una autoridad autónoma metropolitana se mejorará la gestión de los servicios urbanos podría ser delicado. Pongamos el ejemplo de la capital peruana, a la que desde la década de los 70 se le otorgó mediante Ley Orgánica el estatuto de Municipalidad Metropolitana de Lima. A pesar de tener esta categoría especial el equivalente a un rango de nivel provincial, ha sido limitada la capacidad de la autoridad metropolitana para mejorar el sistema urbano y la gestión de servicios, especialmente en el transporte, recolección de residuos sólidos y reducción de la informalidad habitacional. En esta metrópoli 
la calidad de servicios está en proporción a los ingresos económicos de los distritos. De los 46 distritos, solo los que corresponden a estratos medios y altos, que no llegan a más de cinco, tienen servicios relativamente buenos. Esta experiencia indicaría la existencia de otras variables para considerar, más allá de solo incidir en metropolitizar la administración de los servicios urbanos.

\section{A modo de conclusión}

Más allá de estas cuestiones aún abiertas, la lección en la obra de Pirez consiste en mostrar lo dificultoso de planificar un área urbana en donde no existe por parte de la sociedad un sentimiento de pertenencia respecto de un extenso territorio, y cuando la unidad material urbana no siempre coincide con la unidad política que las contiene. El desfase entre el ámbito de gestión y la política es un importante detalle a la hora de planificar los servicios, transportes, medio ambiente y planes de vivienda, sobre todo cuando el vertiginoso crecimiento urbano muchas veces supera la unidad política.

A pesar de que el estudio de caso fue realizado en Buenos Aires, la obra de Pirez es un aporte central para entender la gestión en las demás ciudades latinoamericanas. El encuadre multidisciplinar, los diálogos con otros académicos clave en la región son centrales para mostrar la perspectiva crítica de la ciudad capitalista. La estrategia de aprovechar el contexto de inserción al proceso de globalización para estudiar la gestión de Buenos Aires permite evidenciar las serias dificultades que este fenómeno trae consigo, y advierte a los planificadores tener en cuenta estas cuestiones estructurales de la gestión antes de proyectar nuevas ciudades.

\section{Referencias bibliográficas}

Romero, José Luis (1984). La ciudad burguesa, Buenos Aires, historia de cuatro siglos. T. II. Ed. Abril. 